\title{
Ion Implantation and Annealing of Oxides
}

\section{Citation}

Aziz, Michael J., L. A. Boatner, G. C. Farlow, C. J. McHargue, S. J. Pennycook, J. Rankin, P. S. Sklad, and C. W. White. 1987. Ion Implantation and Annealing of Oxides. Materials Research Society Symposia Proceedings 74: 357-364.

\section{Permanent link}

http://nrs.harvard.edu/urn-3:HUL.InstRepos:2843734

\section{Terms of Use}

This article was downloaded from Harvard University's DASH repository, and is made available under the terms and conditions applicable to Other Posted Material, as set forth at http:// nrs.harvard.edu/urn-3:HUL.InstRepos:dash.current.terms-of-use\#LAA

\section{Share Your Story}

The Harvard community has made this article openly available.

Please share how this access benefits you. Submit a story.

\section{Accessibility}


ION IMPLANTATION ANO ANNEALING OF OXIDES

C.W. WHITE*, L.A. BOATNER*, P.S. SKLAD*, C.J. MCHARGUE*, S.J. PENNYCOOK*, M.J. AZIZ**, G.C. FARLOW***, ANO J. RANKIN****

* Oak Ridge National Laboratory, Oak Ridge, TN 37831

* Harvard University, Cambridge, MA 02138

$\star \star \star$ Wright State University, Dayton, OH 45435

$\star \star \star \star$ Massachusetts Institute of Technology, Cambrioge, MA 02139

\section{ABSTRACT}

Ion implantation damage and annealing results are presented for a number of crystalline oxides. In $\mathrm{Al}_{2} \mathrm{O}_{3}$, the amorphous phase produced by ion bombardment of the pure material first crystallizes in the (crystal-

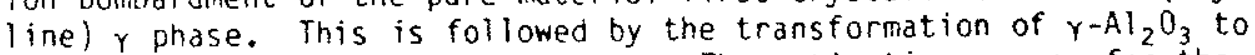
$a-\mathrm{Al}_{2} \mathrm{O}_{3}$ at a well defined interface. The activation energy for the growth of a alumina from $\gamma$ is $3.6 \mathrm{eV} /$ atom. In $\mathrm{CaTiO}_{3}$, the implantation-induced amorphous phase transforms to the crystalline phase by solid-phase epitaxy (SPE). ZnO is observed to remain crystalline even after high implantation doses at liquid nitrogen temperatures. The near surface of $\mathrm{Ka} \mathrm{O}_{3}$ is transformed to a polycrystalline state after implantation at room temperature or liquid nitrogen temperature.

\section{INTROOUCTION}

Numerous investigations of ion implantation damage and subsequent annealing have been carried out for both elemental $S i$ and $G e$ and compound (e.g., GaAs) semiconductors, but there are relatively few reports of similar studies of insulating materials and crystalline oxides. Ion implantation is being increasingly investigated as a method of altering the nearsurface optical, electrical, or mechanical properties of insulating materials $s^{-4}$; and, for many applications, it will be necessary to anneal the implanted material. We are investigating the use of ion implantation to modify the near-surface properties of a number of crystalline oxides. We find that the response of these materials to ion implantation damage varies markedly from one material to another, and that the annealing behavior is also significantly different. In this paper, we compare and contrast the resuits obtained for the cases of crystalline $\mathrm{Al}_{2} \mathrm{O}_{3}, \mathrm{CaTiO}_{3}$, $\mathrm{ZnO}$, and $\mathrm{KTaO}_{3}$.

\section{Experimental Details}

In the case of $\mathrm{Al}_{2} \mathrm{O}_{3}$, a stoichiometric implant ( 2 parts $\mathrm{A}$ ), 3 parts oxygen with ion energies adjusted to give the same projected range liquid nitrogen temperature was used to produce the amorphous phase of pure $\mathrm{Al}_{2} \mathrm{O}_{3}$ on a crystalline a alumina substrate. In this case, a stoichiometric implant was employed so that the crystallization behavior could be determined for the pure material. In the case of $\mathrm{CaTi0_{3 }}$ low doses $\left(\sim 10^{15} / \mathrm{cm}^{2}\right)$ of $208 \mathrm{~Pb}$ were used to turn the near surface amorphous. For $2 \mathrm{nO}$ and $\mathrm{KTaO}_{3}$, the implanted species was $208 \mathrm{~Pb}$ at doses up to $10^{17} / \mathrm{cm}^{2}$. Annealing of the implanted crystals was carried out for time periods ranging from a few minutes to many hours. Annealing environments were $\mathrm{Ar}$ (for $\mathrm{Al}_{2} \mathrm{O}_{3}$ ) or air

tResearch sponsored by the Division of Materials Sciences, U.S. Department of Energy under contract DE-ACO5-840R21400 with Martin Marietta Energy Systems, Inc. 
(for $\mathrm{CaTiO}_{3}, \mathrm{ZnO}$, and $\mathrm{KTaO}_{3}$ ). The crystals were examined in the "as-implanted" state and after annealing hy using $2 \mathrm{MeV} \mathrm{He}$ t Rutherford backscattering and ion channeling measurements. Selected crystals were also examined by transmission electron microscopy (IEM).

\section{Results Ontained in $\mathrm{Al}_{2} \mathrm{O}_{3}$}

Our previous work has established that a stoichiometric implant of A) $\left(4 \times 1015 / \mathrm{cm}^{2}, 90 \mathrm{keV}\right)$ and $0\left(6 \times 1015 / \mathrm{cm}^{2}, 55 \mathrm{keV}\right)$ at liquid nitrogen temperature can be used to produce an amorphous layer ( $1600 \mathrm{~A}$ thick) of pure $\mathrm{Al}_{2} \mathrm{O}_{3}$ on a crystalline a alumina substrate. 5 Annealing of the amorphous material is a relatively complex process that occurs in two stages $^{6}$ as illustrated schematically in Fig. 1. The first sted in the annealing process is the conversion of the amorphous film to the crystalline $y$ phase of $\mathrm{Al}_{2} \mathrm{O}_{3}$. As demonstrated by TEM and RBS measurements, the amorphous $\rightarrow$ y transformation occurs in a matter of minutes at temperatures of $800^{\circ} \mathrm{C}$. The second stepe in the annealing process is the conversion of $\gamma-\mathrm{Al}_{2} \mathrm{O}_{3}$ into $\alpha-\mathrm{Al}_{2} \mathrm{O}_{3}$. This transformation takes place at a well defined interface which moves from the original amorphousicrystal interfacial region toward the free surface. If the crystal is heated for a sufficient length of time, the entire film can be crystallized epitaxially in the a phase as illustrated in Fig. 1 .

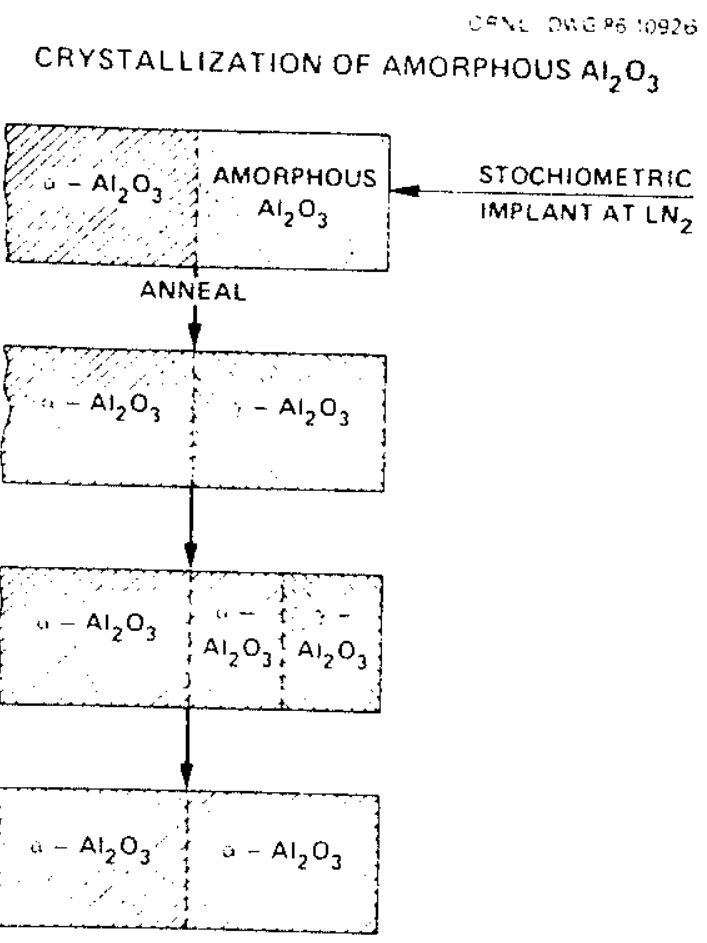

Fig. 1. Behavior observed during the annealing of an amorphous film of pure $\mathrm{Al}_{2} \mathrm{O}_{3}$ on an a substrate.

Figure 2 shows TEM cross section results where the $y \rightarrow$ a transformation is only partially complete. In this case, a stoichiometric implant was used to produce the amorphous layer. The implanted crystal was annealed at $960^{\circ} \mathrm{C}$ for 90 minutes. The TEM cross section results and 
diffraction patterns show that the near surface (region b) is $\mathrm{Y}_{-} \mathrm{Al}_{2} \mathrm{O}_{3}$. Region $\mathrm{C}$ is $\mathrm{a}-\mathrm{Al}_{2} \mathrm{O}_{3}$ formed in the conversion of $y$ to $a-\mathrm{Al}_{2} \mathrm{O}_{3}$. Region $\mathrm{A}$ is the underlying a sibstrate. The interface separating regions $b$ and $c$ is planar and relatively sharp, and this represents the interface where the $y+a$ transformation takes place.

The position of the interface where the $y+$ a transformation occurs in

Fi.g. 2 can be readily measured by TEM or RBS/ion channeling methods. From these medsurements, the kinetics ${ }^{6}$ of the $y+a$ transformation can be determined and these results are shown in Fig. 3 in the form of a plot of the interface velocity versus $Y^{-1}$. Assuming that the $y_{+}$a transformation is thermally activated and that the velocity can be written as $V(T)=$ $V_{0} e^{-Q / R T}$, the experimental data is consistent with an activation energy $Q=3.6 \mathrm{eV} /$ atom. This is the activation energy associated oniy with growth of the a phase from if since the underlying material provides the nucleation sites.

\section{$\gamma \rightarrow \alpha$ PHASE TRANSITION IN AI $\mathrm{O}_{3}$}

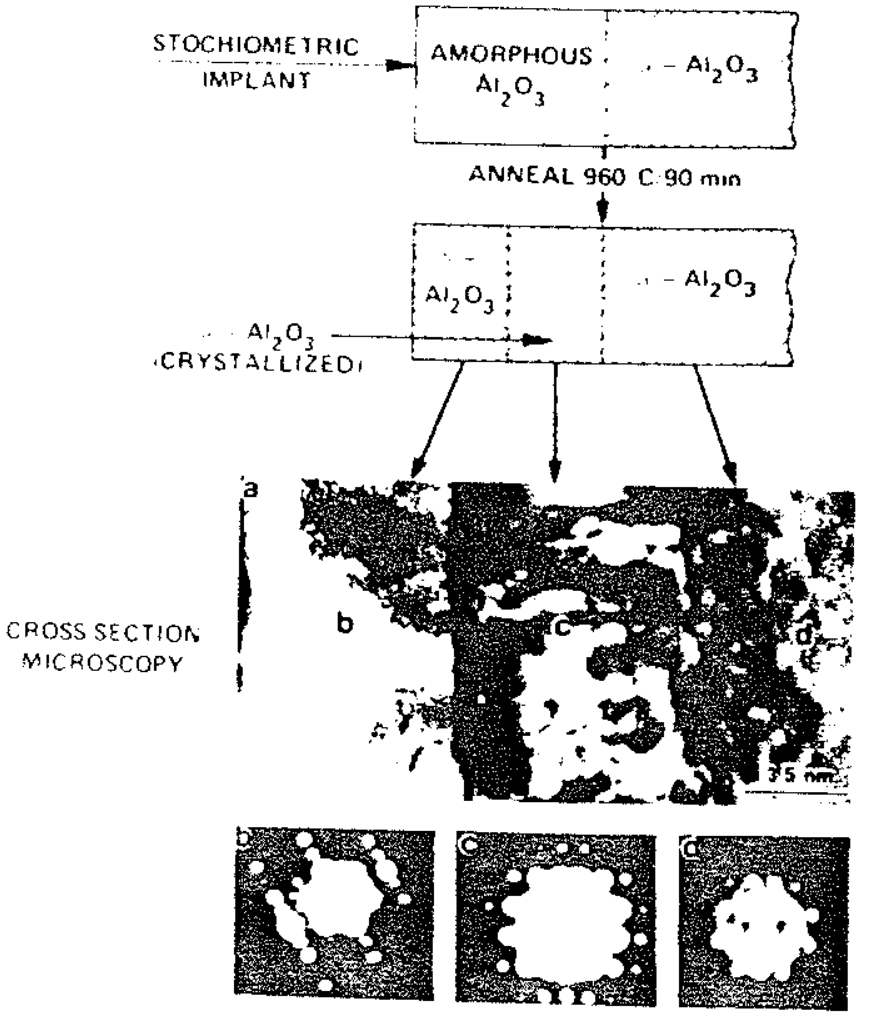

Fig. 2. TEM cross section results showing the $r$ to a phase transition in $\mathrm{Al}_{2} \mathrm{O}_{3}$. The amorphous film was formed by a stoichiometric implant at liquid nitrogen temperature. After annealing at $960^{\circ} / 90 \mathrm{~min}$, the near surface (region b) is $\gamma-\mathrm{Al}_{2} \mathrm{O}_{3}$. Region $\mathrm{c}$ is $a-\mathrm{Al}_{2} \mathrm{O}_{3}$ formed by the $Y+a$ transformation. Region $d$ is the underlying a substrate. 
The ahove measurements refer to the kinetics associated with phase transitions in the pure material. Preliminary measurements using various the presence of impurities. the kinetics can be changed significantly by to some of our previous results addition, by comparing these measurements induced damage is facilitated if , it is clear that recovery from ionthe crystalline but damaged phase.

\section{Results Obtained in $\mathrm{CaTiO}_{3}$}

In the case of $\mathrm{CaTiO}_{3}$, a low dose of implanted $\mathrm{Pb}\left(<101 \mathrm{~s} / \mathrm{cm}^{2}\right)$ at liquid nitrogen temperature is sufficient to turn the near surface region amorphous. Crystallization of the amorphous film occurs by solid-phase phenomenon. Tigure 4 shows RBS-channeling results that illustrate this $\sim 1000 \mathrm{~A}$ deep in $\mathrm{CaTiO}_{3}$. (There is a partial $\mathrm{Cl}$ (Theates an amorphous layer from the $\mathrm{Ti}$ and $\mathrm{Ca}$ sublattices in the astial overlap in the aligned spectra annealing, the amorphous/crystal inter as-implanted state of Fig. 4.) After face in both the $\mathrm{Ca}$ and $\mathrm{Ti}$ sublattices. teristic of solid-phase epitaxy (SPE). This regrowth behavior is characin elemental semiconductors such observed in a material as complex as $\mathrm{CaTiO}_{3}$. It remarkable that SPE can be

KINETICS OF $\gamma \rightarrow a$

TRANSITION IN Al $\mathrm{O}_{3}$
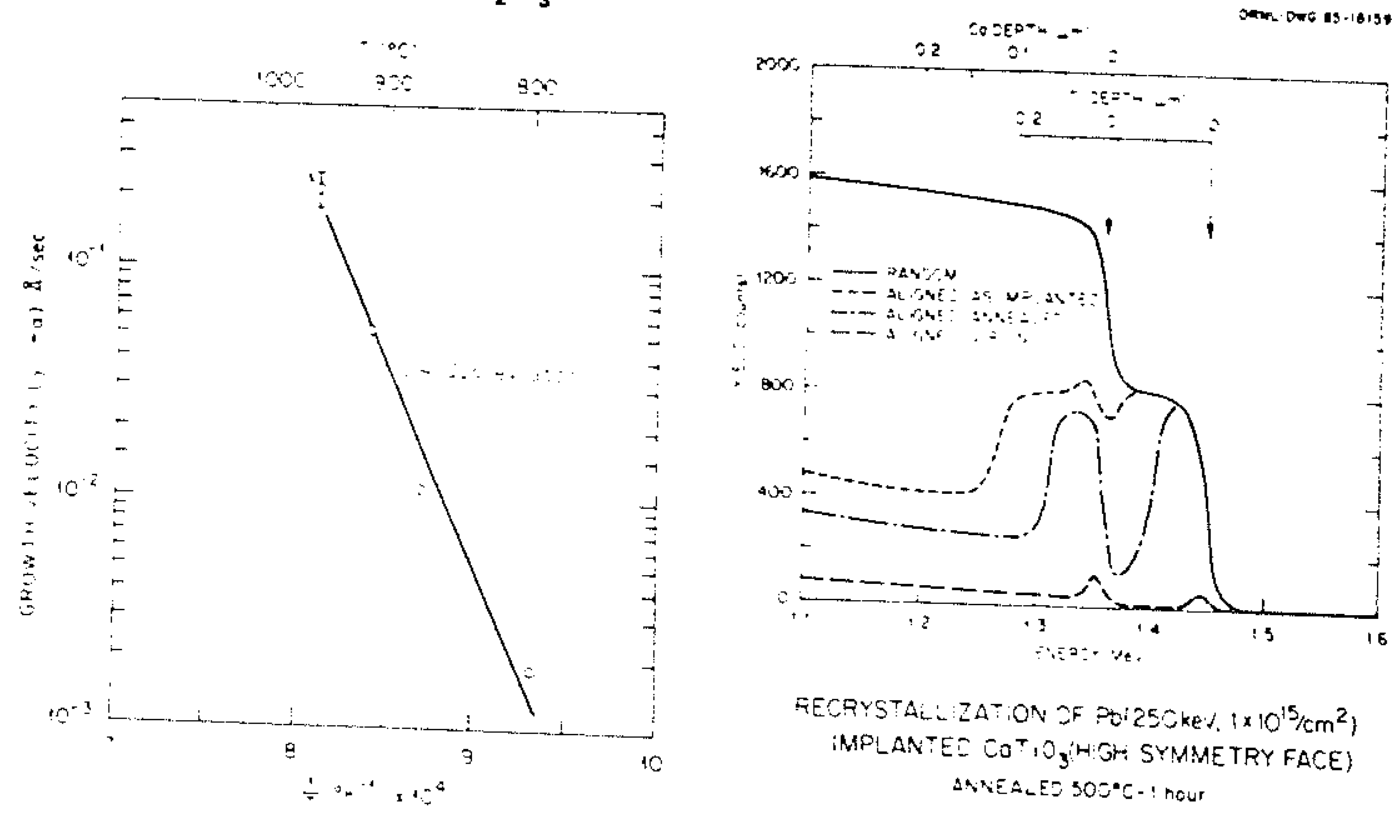

FECRYSTALL:ZATION OF PWI25OkEJ. $\left\{\times 10^{15} / \mathrm{cm}^{2}\right\}$ IMPLANTEE COT1O

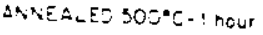

Fig. 3. Temperature dependence of the $\mathrm{Y} / \alpha$ interface velocity in $\mathrm{Al}_{2} \mathrm{O}_{3}$.

Fig. 4. Evidence for solid-phase epitaxy in Po-implanted $\mathrm{CaTiO}_{3}$. Annealing was carried out at $440^{\circ} \mathrm{C}$ for one hour.

Cross-section TEM micrographs for $\mathrm{CaTiO}_{3}$ in the as-implanted and partially recrystallized state are shown in $\mathrm{Fig}_{3}$. 5 . In this case, the crystal 
was implanted by $\mathrm{Pb}\left(1 \times 1015 / \mathrm{cm}^{2}, 540 \mathrm{keV}\right)$ at liquid nitrogen tenperature. This produces an amorphous layer $\sim 1800$ A thick on the crystal substrate. This is illustrated in micrograph (a) and diffraction patterns (d) and (c) taken from the near surface and the underlying region of the material. During annealing, the amorphous/crystal interface moves toward the surface (see micrograph (b)), but diffraction pattern (d) shows that the surface region is still amorphous. In micrograph (b) of Fig. 5 a dislocation band remains at the original amorphous/crystal interface region, the interface is reasonably planar after annealing, and threading dislocations can be observed in the crystallized region.

In $\mathrm{CaTiO}_{3}$, the kinetics associated with the amorphous/crystal transformation along the low symmetry direction have been determined, ${ }^{6}$ and the kinetics are consistent with activation energy of $1.3 \mathrm{eV}$ for growth in this direction. The kinetics associated with growth along the high symetry direction (i.e., the pseudocubic axis of $\mathrm{CaTiO}_{3}$ ) are completely different, and the results suggest a higher activation energy for growth along this direction. These results will be reported in detail in a separate publication.
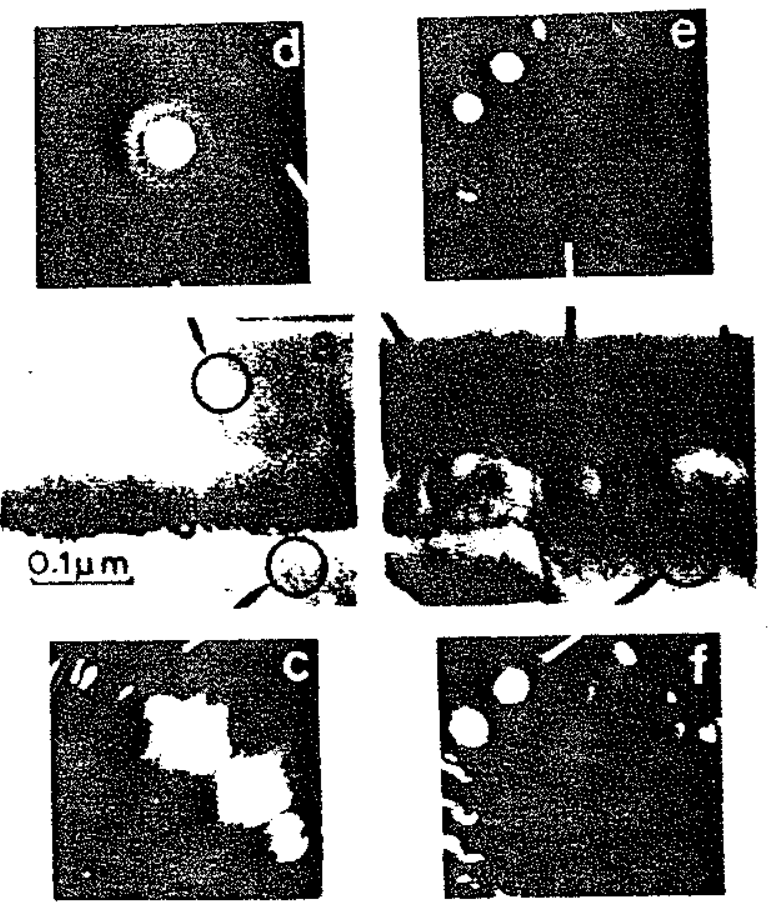

Fig. 5. TEM cross section results from $\mathrm{CaTiO}_{3}$ (high symmetry) implanted by $\mathrm{Pb}\left(540 \mathrm{keV}, 1 \times 10^{15} / \mathrm{cm}^{2}\right)$. Micrograph $(\mathrm{a})$ is the as-implanted state. Diffraction patterns (d) and (c) were taken from the near surface (d) and the underlying substrate (c). Results obtained after annealing at $480^{\circ} \mathrm{C}$ for eight minutes are shown in the micrograph (b). Diffraction pattern ( $f$ ) was taken from the underlying substrate. Diffraction pattern (e) comes from the recrystallized region. The near surface has an amorphous diffraction pattern similar to that shown in (d).

\section{Results Obtained for Zno}

The near-surface region $\mathrm{Al}_{2} \mathrm{O}_{3}$ and $\mathrm{CaTiO}_{3}$ can be rendered amorphous by implantation at liquid nitrogen temperature, but this does not appear to be possible for the case of crystalline ZnO. Figure 6 shows RBS channeling 
results for $2 n 0$ implanted at liquid nitrogen temperature using Po at $360 \mathrm{keV}$ and a dose of $3 \times 1016 / \mathrm{cm}^{2}$. Comparing the aligned spectra taken from the virgin and the implanted regions shows that implantation introduces substantial disorder, but the near surface remains crystalline since the aligned yield does not reach the random yield. Other workers ${ }^{7}$ have reported that 2 no remains crystalline during implantation, and Fig. 6 shows that this is the case even at liquid nitrogen temperature and when very high doses of $\mathrm{Pb}$ are used. The dose of $3 \times 10^{16} / \mathrm{cm}^{2}$ is very near the sputter limit for $\mathrm{Pb}$ in Zno at this energy. Increasing the dose to $1017 / \mathrm{cm}^{2}$ results in only 10\% more po being incorporated in the near surface. The aligned yield from the substrate after the $10^{17} / \mathrm{cm}^{2} \mathrm{implan}$ tation is indistinguishable from that shown in Fig. 6 and demonstrates that even a dose of $10^{17} / \mathrm{cm}^{2}$ is not sufficient to amorphize the near-surface region. These results show that it will be very difficult to amorphize the near-surface region of ZnO by ion implantation, at least down to the liquid nitrogen temperature. Additionally, it may be possible to use other implanted ions to stabilize the implantation-induced damage chemically.

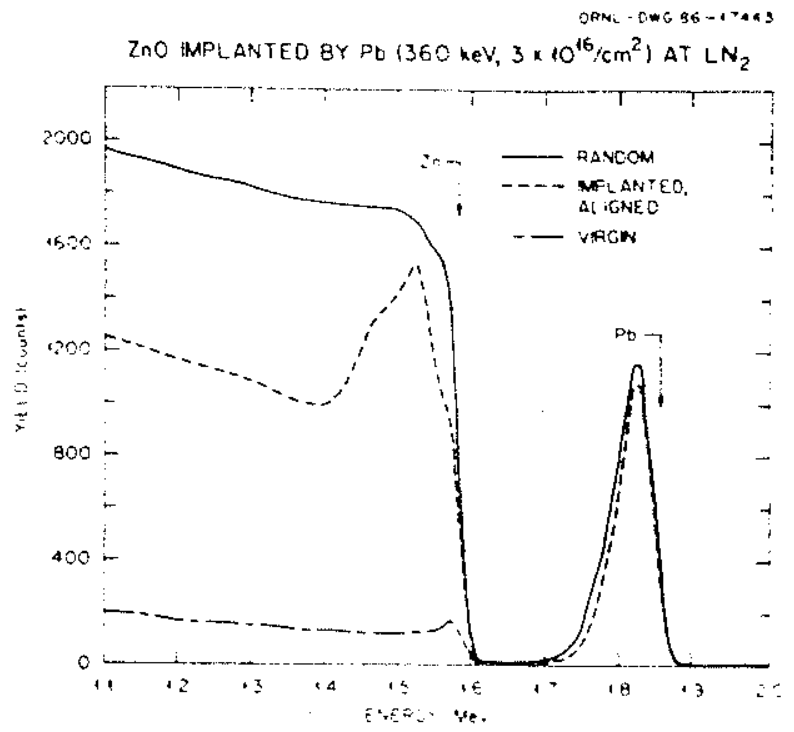

Fig. 6. RBS measurements of a Zno single crystal implanted by Pb. The near surface region has not been fully amorphized as evidenced by the difference hetween the random and aligned-implanted yield in the region between $\sim 1.4$ to $1.6 \mathrm{MeV}$.

\section{Results Obtained in $\mathrm{KTaO}_{3}$}

Of the oxides that we have investigated thus far, the case of KTaO 3 is unique because of the unusual microstructure that develops in the nearsurface region following implantation. This effect is illustrated by the TEM plan view micrograph in Fig. 7 that was taken from a crystal implanted by $\mathrm{Nb}$ at liquid nitrogen temperature. Following implantation, the diffraction pattern shows that the near-surface region is polycrystalline. (The diffraction pattern in the lower righthand corner was obtained from a thicker region of the specimen that includes more of the underlying crystalline material). Individual crystallites several hundred A diameter can be observed in the near surface region. Therefore, in this material, ion implantation of the crystalline substrate has produced a polycrystal: line layer. This effect has been observed for several implanted species following both room temperature and liquid nitrogen temperature implants. 
The mechanism by which the polycrystallites are formed in innimplanted $\mathrm{KTaO}_{3}$ has not been identified. We are not aware of other reports of the formation of polycrystalline layers during the implantation of a crystalline substrate. At present, we are conducting experiments using several implanted species at both higher and much lower implanted doses in order to gain insight into the mechanism of the formation. The results of these experiments will be reported in a future publication.

\section{$\mathrm{K} \mathrm{TaO}_{3}$ IMPLANTED BY $\mathrm{Nb}\left(300 \mathrm{keV}, 2 \times 10^{16} / \mathrm{cm}^{2}\right)$ AT LN 2}

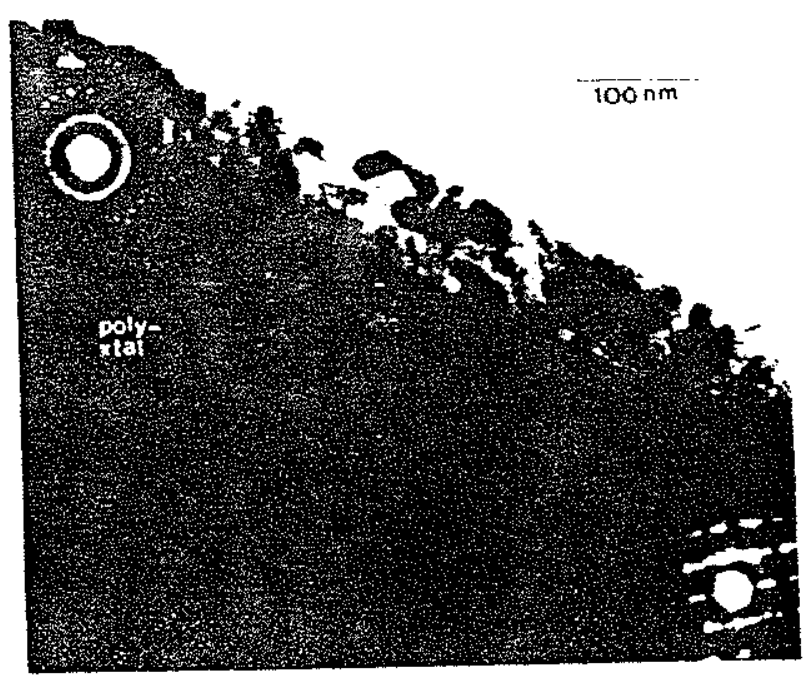

Fig. 7. TEM observations of $\mathrm{KTaO}_{3}$ implanted by vit at $300 \mathrm{keV}$. Electron diffraction patterns taken with this plan view configuration show polycrystallinity at the surface and a superimposed polycrystaline and single crystal pattern at greater defth. The polycrystalline grains comprising the near surface region are clearly visitle in the micrograph.

\section{COHCLUSIONS}

The recrystallization behavior of amorphous $\mathrm{Al}_{2} \mathrm{O}_{3}$ has been studied by using a stoichiometric implant at liquid nitrogen temperature to create an amorphous film of the pure material on a crystalline substrate. Annealing of the amorphous film takes place in two steps. The first step is the transformation of amorphous $\mathrm{Al}_{2} \mathrm{O}_{3}$ to crystalline $\mathrm{r}-\mathrm{Al}_{2} \mathrm{O}_{3}$. This is followed by the transformation of $y-\mathrm{Al}_{2} \mathrm{O}_{3}$ to $a-\mathrm{Al}_{2} \mathrm{O}_{3}$ accompanied by the motion of a planar interface. The activation energy of the growth component of the $r \rightarrow \alpha$ transformation was determined to be $3.6 \mathrm{eV} / \mathrm{atom}$.

in $\mathrm{CaTiO}_{3}$, low doses of implanted Pb are sufficient to turn the rearsurface region amorphous. During annealing, crystallization of the amorphous film takes place by SPE, and the kinetics of crystallization depend on crystal orientation. 
In ZnO, the near surface remains crystalline even after implanting righ doses of heavy ions at liquid nitrogen temperature.

The near-surface region of $\mathrm{KTaO}_{3}$ is observed to be polycrystalline after implantation at room temperature or liquid nitrogen temperature. Further investigation is required to determine the mechanism by which this occurs.

\section{REFERENCES}

1. C.J. McHarque, Nucl. Instrum. Methods (in press).

2. C.J. Mchargue, C.W. White, B.R. Appleton, C.G. Farlow, and J.M. Williams, Mat. Res. Soc. Proc. 27, 385 (1984).

3. P.J. Burnett and T.F. Page, J. Mater. Sci. 19, 845 (1984).

4. H. Naramoto, C.W. White, J.M. Williams, C.J. Mcharque, 0.W. Holland, M.M. Abraham, and 8.R. Appleton, 3. Appl. Phys. 54, 683 (1983).

5. C.W. White, G.C. Farlow, C.J. McHargue, P.S. Sklad, M.P. Angelini, and R.R. Appleton, Nucl. Instrum. Methods B7/8, 473 (1985).

6. C.W. White, P.S. Sklad, L.A. Boatner, G.C. Farlow, C.J. McHarque, B.C. Sales, and M.J. Aziz, Mat. Res. Soc. Proc. 60, 337 (1986).

7. H.M. Naguib and R. Kelly, Rad. Eff. 25, 1 (1985). 